\title{
Curating 'Creative Dystocia': Exhibiting the Relationship between Artists, Identity and Motherhood in Twenty-first Century Australian Art
}

\author{
Courtney Pedersen ${ }^{1 *}$, Rachael Haynes ${ }^{1}$
}

Published: September 10, 2019

\begin{abstract}
The past five years have seen a reinvigoration of debate regarding the significance and impact of motherhood on artists' careers, suggesting that this remains unfinished business for feminism and feminist researchers. Such conversation reflects an ambivalent and ambiguous relationship between motherhood, art and creative identity. While a number of artist-driven initiatives tackling these ongoing concerns have emerged in the United Kingdom and United States, responses in Australia have been less clearly defined. Suspicious of essentialist arguments regarding the maternal in second wave feminist art, contemporary artists are just as likely to address motherhood as an industrial issue as a philosophical position or symbolic motif, suggesting a strategic negotiation of motherhood. Building on previous research analysing the barriers that inhibit women artists in Australia and the creative strategies they employ, this article applies a blended methodological approach to map the current relationship between artists and motherhood. It outlines the curatorial development of an upcoming feminist group exhibition Creative Dystocia, discusses a sample of contemporary artists, and contextualises these historically and conceptually. The intention of this developing curatorial project is to interrupt dominant narratives of motherhood in the Australian context to provide a more deeply textured account of contemporary artists' experiences of motherhood and art-making.
\end{abstract}

Keywords: motherhood, Australian art, creative identity, feminist curation, practice-led research

\section{INTRODUCTION}

The past five years have seen a reinvigoration of debate regarding the significance and impact of motherhood on artists' careers, suggesting that this remains unfinished business for feminism and feminist researchers. This global conversation reflects a stubbornly ambivalent and ambiguous relationship between motherhood, art and creative identity. While a number of artist-driven initiatives directly tackling these ongoing concerns have emerged in the United Kingdom and United States, the responses in Australia have been less clearly defined and less concerned with interrogating the assumptions underlying these current discussions. Suspicious of seemingly essentialist arguments regarding the maternal in second wave feminist art, contemporary artists are just as likely to address motherhood as an industrial rights issue as a philosophical position or symbolic motif, suggesting a strategic negotiation of motherhood that has not yet been adequately addressed in the context of contemporary art. Although it can be argued that Australia has a long and strong history of feminist thought and practice (Lake, 1999), both in art and society more broadly, substantial dialogue and strategising regarding the relationship between art and motherhood is currently largely absent.

Building on previous research analysing both the systemic barriers that inhibit women artists in Australia and the creative strategies they employ (see Pedersen and Haynes, 2015), this paper applies a blended methodological approach to map the current relationship between artists and motherhood. It outlines the curatorial development of an upcoming feminist group exhibition Creative Dystocia (2019-), discusses a sample of contemporary artists, and contextualises these approaches historically and conceptually ${ }^{1}$. 'Dystocia' is the medical term for when the birthing labour fails to progress. In the context of this project, it refers to a failure of creative labour due to the common perceptions of mothering or the structural disadvantages it creates, as well as the difficulties many artists experience when attempting to reconcile creative and maternal labour. As a consequence, the project Creative Dystocia also aims

${ }^{1}$ Creative Dystocia is being developed as a collaborative, artist-driven exhibition project for realisation in Australia in 2020. Originating in Brisbane, its eventual form is being negotiated by an evolving team of artist-mothers and childfree, woman-identifying artists. 
to open up a space for women-identifying artists who are not mothers to consider how perceptions of mothering impact on their practices. As artist-curators, our intention is to interrupt singular or dominant narratives of motherhood in the Australian context in order to provide a deeply textured account of contemporary artists' experiences of motherhood and art-making. The structure of this paper reflects the practice-led nature of creative enquiry, where the creative practitioner makes sense of the field of knowledge through the act of making. While practice-led research has the capacity to yield rich new perspectives on the world around us (Smith and Dean, 2009), Andrew McNamara (2012) points out that it also presents the risk of internal bias and solipsism. Acutely aware of the potential echo-chamber of practice-led research, this paper focuses on the contextual and historical factors that have influenced the developmental curatorial rationale rather than the mechanisms of curating the exhibition. It positions the project of feminist curating within its global context, while pointing out the pressing local factors that have impressed on us the need for additional investigation in Australia.

\section{THE SIGNIFICANCE AND IMPACT OF MOTHERHOOD ON ARTISTS' CAREERS}

As has been observed regularly over at least the past forty years, art has a gender problem (Miller, 2016: 119). Globally, women study art in numbers equal to or greater than men, and yet they are less likely to be represented in exhibitions and museum collections than men (National Museum of Women in the Arts, n.d.; Townsend, 2017; The CoUNTess Report, 2016). The past decade has seen a resurgence in feminist research regarding the dynamics of the visual arts sector. In Australia that institutional critique has been exemplified by The CoUNTess Report (2016), a benchmarking project and online resource on gender equality in the Australian contemporary art sector. The CoUNTess' founder, Elvis Richardson, compiles and analyses data on art education, prizes, funding, art media, organisational makeup, and exhibitions of various kinds across a wide range of galleries including national, state, regional, commercial, artist-run galleries and contemporary art spaces.

Recently, this research was consolidated by The CoUNTess Report (2016), which was based on publicly available data collected from websites, exhibition catalogues, magazines and media in the calendar year 2014. The data indicated that in Australia "those graduating with degrees in fine art or visual art in 2014 were $73 \%$ female and 27\% male, while those with postgraduate degrees were 75\% female and 25\% male" (2016: n.p). And yet almost from the moment they graduate, male artists are more likely to be selected by galleries for commercial representation and curated into exhibitions, with only 40 per cent of commercially-represented artists being women, and only 34 per cent of artists exhibited in state-run museums being women. This statistic becomes even more alarming once artists hit mid-career, where the number of identified practising women artists declines sharply.

As a response to this renewed attention to gender politics in the art world, numerous women-only exhibitions and feminist art retrospectives have been staged in museums and galleries around the world ${ }^{2}$. These exhibitions have provoked heated debates about their potential reinforcement of the art world's patriarchal values, as well as reviving fraught questions regarding biology, social roles and creativity. One reason given for the gender disparity apparent in gallery exhibitions and museum collections is the supposed incompatibility of motherhood with the role of being an artist (Gratton, 2017). Creative Dystocia addresses this assumption through the collaborative development of a group exhibition utilising feminist curatorial methods. It also investigates the current relationship between motherhood, creativity and visual arts in Australia.

\section{RELATIONSHIPS BETWEEN MOTHERHOOD, ART AND CREATIVE IDENTITY}

An overview of the literature regarding the relationships between motherhood and art reveals that women artists with mothering responsibilities generally report that being a mother has a positive influence on their art because they encounter new experiences, emotions, and imagery, which all inspire new creative work (Summers and Clarke, 2015). Even those who do not employ direct imagery of pregnancy or motherhood in their work indicate that the experience of seeing the world in a new way is influential (Power, 2008). This is notable, given the common belief that motherhood (or perhaps more accurately, the duties of mothering) diminishes an artist's creative capacity, or as Andrea Liss (2009) describes it, 'the lie that women, especially mothers, are not or cannot be thinking, critical human beings' (xiv). While many artists believe that motherhood has a positive impact on the

\footnotetext{
${ }^{2}$ See for example: WACK! Art and the Feminist Revolution, Museum of Contemporary Art, Los Angeles, USA (2007); Global Feminisms, The Brooklyn Museum, New York, USA (2007); elles@centrepompidou, The Pompidou Centre, Paris, France (2009); Contemporary Australia: Women, Gallery of Modern Art, Queensland, Australia (2012); Unfinished Business: Perspectives on Art and Feminism, Australian Centre for Contemporary Art, Melbourne, Australia (2017).
} 
art they make, they simultaneously say it diminishes the time available for making it (Brooks and Daniluk, 1998; Power, 2008; Summers and Clarke, 2015).

One of the inherent tensions experienced by artist-mothers is that child-rearing and making art use the same resources: time, focus, energy and inspiration. Many artists point out that these resources are limited, and consequently, must be carefully allocated to either mothering or art practice (Ciciola-Izzo, 2014; Power, 2008). Kirschenbaum and Reis' 1997 comparative study of ten female artists, for example, made these tensions between the desire and motivation for creative work and the demands of motherhood very clear. Social expectation dictates that mothering should be prioritised and many artist-mothers report feelings of guilt when they put their needs for creativity above their children's needs. However, as Kirchenbaum and Reis (1997) note, mother-artists remain hopeful about the future capacity to dedicate themselves more fully to art:

The same factors also contributed to their creative process and the development of their identity as artists, their awareness and passion for their life and art, and their love of family and work. Whether or not any of these artists ever achieves the status of eminence cannot be determined at this time. What does seem clear is that because they are both artists and mothers, eminence may not be of ultimate importance in their lives because the creativity of each of these artists was expressed not only in their creative art products but also in their creative efforts in raising their children and nurturing their families. This provided frustrations for all of the participants in this study, but none of the artists regretted having children, and all looked forward to time later in their lives in which additional hours could be devoted to their art (263).

In recent years, the message to young artists has become more negative. From 2014 onwards, a number of mainstream media and online think pieces circulated, inferring once again that motherhood and artistic success were incompatible. For example, the BBC Two Artsnight episode The Pram in the Hall used Cyril Connolly's famous quote regarding parenthood as the 'enemy of good art' as the starting point for a discussion of whether 'children inhibit a creative life' (Artsnight 2015), and the Australian author Kate Holden was quoted as saying, 'You know those photos of the American dustbowl in the 1930s where the families literally walked off their land, leaving half eaten bowls of cereal on the kitchen table? That's what it felt like happened to my work when I had a baby' (in Williams, 2016: n.p).

Common themes emerge in studies of art and motherhood, including: the common assertion that art and motherhood are fundamentally incompatible due to the rigorous requirements of a successful art practice (Miller, 2016); that art making and mothering are both 'soft' tasks and therefore compatible with each other (Stohs, 1992); the deep two-way guilt of both artist/mothers and non-mothers, concerned that any decisions they make regarding art and parenting will be 'wrong' (Kirschenbaum and Reis 1997; Reis 2002; Ciciola-Izzo 2014); and the apparent blindness to the necessary 'third stream' where both working artists and mothers are required to undertake additional paid work to support themselves and their families (Crane, 2011). From the perspective of the mothers themselves, there are often positive impacts, both on their mothering and their art practice (Summers and Clarke, 2015). There remains however, some concern among contemporary artists that depicting motherhood in art risks 'being labelled saccharine, sentimental, and kitschy' (Kutis, 2013: 1).

Is the representation of motherhood for artists as an epic battle between competing desires and social imperatives accurate, or is something more complex and slippery being missed in this analysis? In the recent discussions, easy assumptions have been made about those women artists who are not mothers. Beyond the overtly antagonistic opinions of prominent artists such as Tracey Emin (Alexander, 2014) and Marina Abramovic (Neuendorf, 2016), whose views reinforce the narrative of motherhood and artistic success as mutually exclusive, there is little nuanced discussion of whether perceptions of motherhood also impact on women's artistic practices or the decisions they make regarding their careers. As Gayle Letherby (2018) has pointed out, voluntary and involuntary childlessness is often a continuum or an evolving status for women, rather than a single point of identification - and ambivalence about one's status can be experienced by both those with children and those without (246). There is also the risk, as Jennifer Stuart (2011) has indicated, of artistic output by childfree women being interpreted entirely as a substitute procreative activity; an attitude that elides the complexity of women's lives:

To view the creative artist's product as equivalent to, or substitute for, a baby would demean the many other possible motivations for its creation. And yet there is certainly potential for the artist's creationthe painting, the symphony, the novel, the screenplay — to represent both her fantasied child and a version of herself (among other people and things) (418). 


\section{ARTISTS' RESPONSES TO MOTHERHOOD, CREATIVITY AND LABOUR}

Depictions or representations of motherhood appear in the work of women artists throughout history. Élisabeth Louise Vigée Le Brun's eighteenth-century self-portraits with her daughter or Berthe Morisot's Impressionist studies of motherhood, such as The Cradle (1872) provide an affectionate view of mothering from a feminine perspective. Much work that emerges during second wave feminist practice however, moves from motherhood as a subject of art to its matter (Lindau, 2016). In her study of maternality in Yoko Ono's practice, Elizabeth Ann Lindau discusses the artistic production of the late 1960s and 1970s as a galvanising moment in the relationship between art and motherhood. Citing projects like the Mother Art collective, Mary Kelly's Post-Partum Document (1976) and Susan Hiller's Ten Months (1977-79), Lindau reinforces Ono's claim that motherhood could be 'an artistically creative as well as procreative force' (Lindau, 2016: 72). Given this generation of artists' enduring significance as feminist practitioners and the influence Ono and Kelly have had on the current generation of contemporary artists, it is not surprising to see evidence of these approaches in current practice. Similarly, Mierle Laderman Ukeles' works from 1974, Fall Time V ariations III, Children's Piece, Time Stop and It's Okay to Have a Babysitter have been revisited by younger artists due to retrospective exhibitions of the Maintenance Art Works between 2013 and 2016, in Austria, the United Kingdom, Sweden, the United States and in Brisbane, Australia - the location of the Creative Dystocia project. As Andrea Liss explains (2004):

The art world patriarchy tried to make Ukeles cut off part of herself in favor of the other. It was unthinkable for a woman to be an artist and a mother. She had a brilliant idea. Rather than give up, which was decidedly not an option, Ukeles wisely and outrageously took the matter-of-fact stance that her maternal work was the material from which art and cultural commentary could be made (26).

In the Australian contemporary art context, art about motherhood is perhaps best exemplified by the work of Del Kathryn Barton, whose self-portrait with children ${ }^{3}$ won the Archibald Prize, a high-profile Australian portraiture award, in 2008. She followed this with a similar family portrait of the actress Cate Blanchett, Mother (a portrait of ( Cate) in 2011. These paintings, although executed in a highly decorative, expressionistic style, are the descendants of Vigée Le Brun's court paintings of over 200 years earlier. In each of these works, a dignified mother figure collects her children to her in a protective or proprietorial way, surrounded by flora, while also performing mudra-like hand gestures. The mother is presented like a goddess-queen. While the popularity of these works indicates the resilience of motherhood as a popular romantic subject, contemporary approaches to motherhood by women artists are often more pragmatic.

One of the characteristics of contemporary art practice has been the growing professionalisation of the artist's role - or perhaps even its 'hyper-professionalization', as Daniel S. Palmer (2016) describes it. As artists have been encouraged to view their practice as a career rather than a critical vocation, there are increasing intersections between the issues they encounter and those experienced by the wider workforce. Attempts to address motherhood as an industrial issue for the arts are regularly stymied however by the distinctive differences between work arrangements. While most women workers have legislative protections against discrimination on the basis of pregnancy or parenthood, and access to some form of maternity leave, a majority of artists are freelance or selfemployed (Throsby and Petetskaya, 2017: 10). As precarious workers with carer responsibilities, women artists find themselves at the pointy end of neoliberalism, with its emphasis on individualised empowerment and the dismantling of collectivised labour negotiations. As Elizabeth Humphrys (2018) points out, the rise of neoliberalism took on a unique complexion in Australia, where it developed under a structured agreement between government and the trades union movement, rather than in politically conservative arenas as elsewhere (3). This has implications for both their subjective position in the world, as Katarzyna Kosmala (2017) has pointed out, and for the more prosaic logistical aspects of their lives. Given this political 'squeeze', it is little wonder that artists are creating artwork in an attempt to re-order the world of work. In this regard they are also echoing Ukeles' declaration in her 1969 manifesto that there are important parallels between the processes of maintenance (including the chores of motherhood) and some art processes:

Avant-garde art, which claims utter development, is infected by strains of maintenance ideas, maintenance activities, and maintenance materials. Conceptual \& Process art, especially, claim pure development and change, yet employ almost purely maintenance processes (1969:2).

Artist activists with a focus on the particular experiences of motherhood continue to emphasise this principle of maintenance labour in the work that they carry out. A number of recent artist projects address the persistent gaps between professionalisation, career maintenance and the circumstantial conditions of artists' lives with regard

${ }^{3}$ Del Kathryn Barton, You are what is most beautiful about me, a self portrait with Kell and Arella, 2011 
to motherhood. In the United States, the voluntary community organisation, Cultural ReProducers (established in Chicago in 2012 by the artist Christa Donner) places an emphasis on the collective benefit of resource sharing and truth telling. In her 2016 web article 'Who Cares for Whom? Parenthood in the Creative Community', Donner implores artists to own and acknowledge their parenting identity. Her suggestions include mentioning parenthood during artist talks; acknowledging the impact of child-raising when applying for funding; taking children along to art world events; referencing creative foremothers (the canon of artist mothers); rescheduling events to more child-friendly times; reconfiguring spaces and events to be more inclusive; and crucially, asking what payment is being offered for creative work. These strategic approaches acknowledge the barriers that are encountered by artist parents and importantly, indicate that collective and structural remedies are required.

What can artists do if they do not have access to a physical network for support or collective action however? Pittsburgh-based practitioner, Lenka Clayton initiated a home residency programme for herself in 2012. Titled $A n$ Artist Residency in Motherhood (ARIM), this self-designed artistic program resulted in a number of proposed and realised artworks as well as associated professional paraphernalia such as a manifesto (or artist's statement), business cards, signage and a website. With the assistance of mentors, studio visitors, and grants from the Pittsburgh Foundation and the Sustainable Arts Foundation, Clayton's project enabled her to continue both her creative and professional development as an artist. Clayton has since extended an invitation to other artist-mothers and in 2018 said over 600 artists-in-residence were participating in this project (Clayton, n.d.). While on the one hand, ARIM can be read as a practical response to the enduring problem of maintaining the discipline of an art practice in the midst of the chaos of parenting, it can also be interpreted as a political provocation, asking why it is that women artists are required to become the mothers of invention when it comes to sustaining their creative work.

A number of proof-of-concept or pilot projects seeking to reconcile mothering with creative work have been established in recent years. In the United Kingdom, The Mother House Studio model was initiated in 2016 by the ProCreate Project, an arts research and advocacy organisation established in 2013. The Mother House ran integrated studio spaces and day care programs for six months in London, Waterloo and for a fortnight in the town of Stroud, before opening in Dagenham with support from Create London. This project responds to the lack of affordable and equitable childcare available to women and explicitly draws a connection between the 'creative health' of mother artists and healthy communities:

The project demonstrates potential to benefit the well-being of women artists by enabling them to make work during pregnancy and motherhood, sustain their artistic identity and confidence, and access a supportive peer-community, in-turn developing healthy families and young people (The Mother House, 2017).

Taking its cue from An Artist Residency in Motherhood, the Mother in Arts residency was run as a pilot project in Amsterdam in 2017. The participants-- four women artists who are also mothers - entered into the Mother in Arts program with funding from the Mondriaan Foundation. Collective and mutual child-care was provided in one of the artist's homes, while the women realised their artworks in a nearby studio complex, the artist-run space Goleb at de Vlugt. The premise of this residency program was that, given the right conditions, artist-mothers can continue to have successful artistic careers even during the particularly taxing period of early parenthood while still being deeply invested in the wellbeing and development of their children — or as the project's statement reads, 'Being a mother is not a stigma; motherhood can accompany a successful artistic practice' (Mother in Arts, 2017). Mother in Arts culminated in the exhibition Re: Production, with work by the participating artists: Cecilia Bengtsson, Cecilia Cavalieri, Aurora Rosales and Csilla Klenyanszki. Given the project's determination to connect a deep commitment to rich childhood development with art practice, it is unsurprising that the works included in the exhibition dealt with issues such as the intersubjective dynamics of mothering, parallels between mothering and ecological/political awareness, women's labour, and the precious nature of time. Crucially, it is the principle that 'women have to remain part of the art community after they've become mothers' (Mother in Arts, 2017) that underpinned the project, indicating that for many younger artists, even in relatively equitable countries like the Netherlands, this still feels like a significant challenge.

In Australia, the collective Art/Mums has functioned as a framework for a group of Melbourne artists to collaborate and support one another as they navigate the assumption that motherhood is an impediment to art practice. Carefully describing themselves as 'a group of artists who are also mothers,' Art/Mums members have included Clare Rae, Hanna Tai, Claudia Phares, Gabrielle de Vietri, Clare Needham, Eugenia Lim and Jessie Scott - all artists with distinctive practices of their own. The formation of this group references the consciousnessraising collectives of second wave feminist art activity, but with specific reference to the potentially career-limiting aspects of motherhood. Rather than originating in an activist impulse, Art/Mums arose organically from preexisting friendships and provides mutual support for its participants: 
Working with concerns and restrictions related to parenting and maintaining an art practice, they seek to unpack concepts that give a voice to their experiences. They hope the group represents what it is to work as an Art/Mum and in turn act as a resource for future generations (Art/Mums, 2017).

Generally, projects regarding art and motherhood in Australia have been less aimed at actively improving the welfare of mother-artists and their children and more about women artists rediscovering a creative identity for mothering that became less visible after the end of the activism of the 1970s and 1980s. It is interesting to consider why this has been the case. It is not for a lack of need; Australia ranked a disappointing 35th in the most recent World Economic Forum's 'Global Gender Gap Report' (2017) and a national survey undertaken by Macquarie University in collaboration with the broadcaster SBS revealed persistent and rigid beliefs regarding gender roles as well as disturbingly high rates of gendered harassment (SBS, 2018). In this context, women artists experience a layering of disadvantage that sometimes appears insurmountable. A small number of exhibitions focussed on the experience as well as the politics of mothering have taken place in Australia over the past five years. For example, Claire Needham curated the group exhibition MUM in 2016, including work by Catherine Bell, Erika Gofton, Kate Just, Ilona Nelson, Clare Rae, Nina Ross, Hanna Tai and Meredith Turnbull and Roma Turnbull-Coulter (Needham, 2016; Romensky 2016). In the same year, Kym Maxwell staged an exhibition, Parenting is Political at Bus Projects in Melbourne, with contributions by Aurelia Guo, Anastasia Klose and Angela Brennan. This emerged as a response to a panel discussion "Parenting in the Art World", held as part of the exhibition, Re-raising Consciousness, curated by Fayen De'Evie, Harriet Morgan and Katherine Hattam at TCB, another Melbourne artist-run space in 2014. Emerging curator, Zorica Purlija brought together 16 early-career and established artists for the exhibition of image-based works, Realising Mother in Sydney in 2017. Once again, this exhibition harked back to earlier arguments regarding the tensions between art and mothering, citing 'the Women's Art Movement in Australia (formed in 1974) and Catriona Moore's book Indecent Exposures (1994) as significant contributions to interpreting the role of women and mothers in contemporary society' (Purlija 2017).

Artist-mothers, and curators determined to exhibit their work, appear highly cognisant of the well-worn territory they are traversing when they discuss both the benefits and barriers experienced by women while parenting. The regular repetition of an adversarial relationship between family and art raises the suspicion that some other agenda is served by relentlessly pitting one against the other. What purpose is served, for example, by disregarding the 'third shift' experienced by most artist-mothers in Australia: the need for an income source beyond their art practice? In Australia the annual median income for a visual artist from all creative arts-related sources is a tiny $\$ 12,000$ (Throsby and Petetskaya, 2017: 74). Given the inequitable situation experienced by women, this figure is likely to be substantially lower for them. By looking at the practices of artists whose works refer to the dynamics of motherhood but do not rehearse its assumed antagonistic relationship with art, we can be prompted to problematise this narrative.

Australian artists, Catherine Bell and Anastasia Klose have both used their work to describe and push against the normative expectations of motherhood. The 'bad' or 'neglectful mother' is a spectre that haunts many women artists. Bell's artworks, Making a Baby and Baby Drop, where lurid cake sculptures of babies were given to women to slice open or were left in public baby change rooms, were deliberately transgressive and elaborated on the ambivalent sensations many women feel about motherhood, both as mothers or not (Aamalia, 2008). Bell explained her production of these works as a cathartic expression of her own anxiety regarding the 'bad mother' as well as a point of connection with other women:

The creation of this cake as a scapegoat, embodying the sadness realised by the abuse inflicted on children and the ever-present threat of infanticide in our community, has a personal and public function. The trance like state induced by the repetitive act of icing is embedded with mixed narratives of joy and pain. Case studies of the women who have killed innocent babies merge with the elated tales of friends whose babies have just entered the world. Making this cake indicates two orders of exorcism, originating as a personal catharsis and extending to become an act and art of public exorcism or scapegoating (2011: n.p).

While Klose's work often explores her close relationship with her own artist mother, it is her maternal feeling toward her beloved dog Farnsworth that she describes as a panacea for her grief regarding the art world's brutal realities and commercial imperatives (Klose, 2017). A different set of complexities arise for First Nations artists in Australia. While many women artists agonise over the tensions inherent to the relationship between mothering and making, Aboriginal mothers additionally battle the racist presumptions of 'neglect' or 'bad mothering' that are still used to justify the removal of children from their Aboriginal families (McQuire, 2015). As Aileen MoretonRobinson has pointed out, white feminism has been grossly inadequate in comprehending and accounting for Indigenous experience (Moreton-Robinson, 2000). It is in this context that artist and curator Paola Balla has 
articulated her prioritising of 'Blak Matriarchy' over a generic feminism that fails to account for the often-violent dispossession of Aboriginal mothers (Balla, 2018; Perkovic and Balla, 2018).

What this brief discussion of a small sample of contemporary art practices and art projects indicates is that despite the common analogy of art-making and child-rearing as parallel creative activities that make demands on the same set of resources, the relationship between art and motherhood is never simply a single tension, but rather a complex interplay of broader economic, political and social issues with individual and collective desires and values. We can continue to represent motherhood in all manner of ways, both/either as a joy and/or as a burden for women artists, but it will not necessarily open up our understanding of how women artists navigate and negotiate practice and/or motherhood. Therefore, this textual and visual analysis of creative examples by Australian contemporary artists simply provides a conceptual framework for the development of Creative Dystocia. The development of curatorial approaches to the exhibition will be discussed in the next section of the paper, which addresses key debates about feminist curating and outlines an understanding of the curatorial process as feminist method.

\section{CURATORIAL APPROACHES TO CREATIVE DYSTORIA}

This section addresses the relationship between feminist curatorial methods and exhibitions that deal explicitly with women's experiences, including the subject of 'motherhood', which occupies a complex and contested position in histories of feminist art. A key aim of this research is developing feminist curatorial approaches to exhibitions as a central investigative method. This section will outline current debates surrounding feminist exhibition-making and reframing of the all-women exhibition. It will discuss the development of our curatorial approach for this project through a framework for 'curatorial care.' Therefore, the resulting group exhibition Creative Dystocia, will form part of the research process through the active negotiation of this framework.

\section{FEMINIST APPROACHES TO EXHIBITION-MAKING}

Art institutions were identified as contested territory by feminists in the 1970s, who recognised the politics of exclusion in operation. In response, there were two key feminist strategies employed in relation to exhibition making - agitating for the inclusion of women artists in museum exhibitions, and initiating alternative spaces for women artists to create communities and present their artworks. An example of the first strategy is the 1976 exhibition Women Artists, 1550-1950, organised by Ann Sutherland Harris and Linda Nochlin at the Los Angeles County Museum of Art (LACMA). As Harris recounts in the catalogue, this exhibition was initiated by the director of LACMA, in response to the demands of women artists for equal exhibition time (Harris and Nochlin, 1976: 8). Key examples of the second strategy were the establishment of Womanspace Gallery in 1972 and the Woman's Building in 1973 in Los Angeles, which operated until 1991. These were created as alternative spaces to the male dominated, patriarchal power plays of commercial art galleries and state museums.

The primary function of feminist organisations and communities was to provide the space necessary to support women's art practices. As Katy Deepwell (2006) notes in the essay, Feminist Curatorial Strategies and Practices since the 1970s, 'The exhibition site became an opportunity for public debate about the possibilities of new forms of art practice, new spaces and new audiences' (75). However, the separatist nature of these alternative spaces was considered problematic by some feminists, who argued for greater inclusion for women artists in established art museum exhibitions and collections. Another criticism levelled at 'alternative' spaces by feminists, was in relation to the politics of exclusion, and the persistent dominance of white, middle-class perspectives.

Over the last decade there has been a resurgence of institutional interest in art by women, and in feminist art, as evidenced through the staging of a number of major exhibitions (Robinson, 2013: 129). Exhibitions in this period have adopted a survey style approach, which reflect the historicisation of feminist art, for example $W A C K$ ! Art and the Feminist Revolution (Museum of Contemporary Art, Los Angeles), the intersectional approach of Global Feminisms (Brooklyn Museum, New York, 2007), or focus on specific geopolitical or geographical frames such as the 'blockbuster' Contemporary Australia: Women (Gallery of Modern Art, Brisbane in 2012). Following the two key exhibition strategies employed in the 1970s, elles@centrepompidou (The Pompidou Centre, Paris, France 2009) was a critical intervention in this major museum in Paris, while the establishment of the Elizabeth A. Sackler Centre for Feminist Art at the Brooklyn Museum, New York in 2007, functions as a dedicated space for feminist art.

\section{REFRAMING THE ALL-WOMEN EXHIBITION}

The development of Creative Dystocia takes place in the context of a recent 'curatorial turn' in feminism over the last decade, constituting a proliferation of major 'all women' exhibitions (Dimitrakaki and Perry, 2016: 220). Recent 
debates in feminist curating question the women-only exhibition format as potentially replaying the exclusionary politics of the art museum, and exhibitions that deal explicitly with womanhood as problematically essentialist (Hedlin Hayden and Skrubbe, 2010: xiv). In a similar way to the criticism aimed at women-only alternative institutions of the 1970s, the debate continues about the efficacy of separatist (or essentialist) strategies. As Hedlin Hayden and Sjoholm Skrubbe argue in Feminisms is Still Our Name: Seven Essays on Historiography and Curatorial Practices (2013), continuing to position women artists and art by women as 'alternative' narratives, acts to shore-up the normative, that is, dominant patriarchal position. They claim that, by

Pursuing the contextual space of the/an alternative, one also keeps (re-)framing the prevalent trajectory in art historical practices: namely a sex-biased structure (...) Do women artists and art by women still need to be defined and employed as a mode of challenge, on the very basis of them being alternative? (xiv).

On the other hand, feminist curator Maura Reilly in an interview with Lara Perry argues for the relevance of women-only exhibitions as a 'curatorial corrective', to achieve gender equality in the art world (2016: 50). While accepting the 'essentialist' nature of such an approach, Reilly draws on Gayatri Chakravorty Spivak's conception of 'strategic essentialism' (Spivak, 1987: 281) to argue: “one might temporarily accept the category of 'woman' as a stable unity for the purposes of mobilizing women in feminist political action" (Reilly, 2016: 50). Like Reilly, curator Dorothee Richter (2006) argues for affirmative action as a central strategy of feminist curating, advocating for gender equality through numbers, and seeing this as a 'temporary strategy, a support structure on the way to diversity and multiplicity beyond fixed categories as a horizon' (64). In an Australian context, the CoUNTess report on numbers of women artists represented in major exhibitions and collections provides evidence that there is still an important role for feminist curating to play in affirmative action. However, beyond just a numbers game, Hilary Robinson (2013) reminds us that we need to continually ask, 'what feminist politics informed these exhibitions, and what feminist politics did they produce?' (147).

One of the key framing questions for the project Creative Dystocia is: how can we re-frame the contemporary women-only art exhibition in light of these debates, specifically when negotiating the nexus of motherhood and creativity? As Katy Deepwell (2006) notes, 'the women's art movement emerged through group exhibitions and acts by women artists organized thematically and polemically around feminist issues' (75). Exhibition making has played a pivotal role in feminist art politics since the 1970s, both as a form of intervention into art's patriarchal institutions and as a strategy for alternative space-making. As Jenni Sorkin comments in her 2007 essay for the exhibition WACK! Art and the Feminist Revolution, the all-women exhibition format manifests itself as the deterritorialisation of traditional group exhibition practice, 'an unintended history of resistance' (461). The recent 'curatorial turn' in feminism has constituted a proliferation of all-women exhibitions and surveys, once again foregrounding feminism's critical role in the contemporary art institution. In Politics in a Glass Case: Feminism, Exbibition Cultures and Curatorial Transgressions (2013), Angela Dimitrakaki and Lara Perry problematise this relationship between the political agency of feminist practice and the 'neutralising' space of the art museum or exhibition. Creative Dystocia aims to address the gender politics of inclusion and exclusion at play in the contemporary art gallery, and indeed, in the professional life of women artists.

\section{FEMINIST CURATORIAL METHODS}

As a lack of exhibition opportunities has been identified as a significant barrier for women artists, the curatorial role is potentially a problematic one, inferring as it does the highly gendered dynamics of gate-keeping, quality discernment and the care of an artist's oeuvre. What are feminist methods of curatorial practice and how can they be identified? While feminist curating has been commonly characterised as fixating on subject matter and the intent of the artist, contemporary analyses of curatorial practice seek deeper patterns of understanding method and ethical engagement. As Devon P. Larsen (2006) argues there are a range of significant feminist strategies that have been absorbed more broadly in exhibition practice including the recognition of exclusions, embracing multiple perspectives and allowing contradictions to remain (96).

It is important to distinguish between exhibitions of 'women's art' and exhibitions curated from a feminist point of view. As Katy Deepwell (2006) argues, an exhibition of art made by women is not necessarily a feminist one (68). By the same token, as Renee Baert (2000) asserts, feminist 'research, issues and methodologies may be folded into other projects, rather than existing in a designated space apart' (6-7). These dialogues about contemporary feminist curating inform our approach to exhibition making.

One of the key characteristics of feminist curating proposed by Dorothee Richter (2016) is the embedding of institutional critique in projects. Richter asserts, 'To take into account the structural and material side of curating means - again - to think of feminist curating as involved in and part of political and economic struggles' (67). She 
goes on to argue that this would also question any hierarchical positioning between curators and artists (66). This provocation reveals the deeply entrenched power dynamics of the art world and its gallery system. It lays down a challenge for feminist curators and brings into question authorship, responsibility and reputation - which are the foundations of building professional careers. It is not easy to work in a state of 'risk' - that is to say, collaboratively, which is a relationship of trust and obligation.

The dominant approach to contemporary curating is framed in terms of a selection process, whereby the curator is an expert who chooses artworks from a range of possibilities and thus determines the exhibition form. This is exemplified by Jens Hoffman (2009), who comments:

We concur that the curatorial process is (...) an imposition of order within a field of multiple (and multiplying) artistic concerns." In this conception of the exhibition process, a curator's role is, "precisely to limit, exclude, and create meaning using existing signs, codes, and materials. (2009).

This approach to art curating can be seen as deeply problematic from a feminist, inclusionary perspective. It positions artworks as interchangeable ideas, disconnected from artistic labour. Dorothee Richter (2016) critiques the proposition of curator as 'chooser,' arguing that this limits curatorial practice to one of 'excluding positions' (66).

While the traditional image of the curator as the carer of material objects has been replaced by an authorial role (the 'making of meaning'), the ethics of care can easily be applied to the personal histories and conceptual concerns that underpin the work of contemporary women artists. In considering our approach to curating a feminist exhibition, we have asked ourselves how can we, contrary to the dominant definition of current curatorial work, open, include and amplify meaning through exhibition making?

\section{FRAMEWORKS FOR CURATORIAL CARE}

The reframing of relations in the curatorial process is key to the collaborative conversations that are informing this project. This collaborative approach builds on dialogic methods in curatorial practice as research and the potential of conversation as a key feminist strategy in exhibition making. As a feminist curatorial method, the dialogic pertains to establishing non-hierarchical relations between curators and artists, and reframes the feminist exhibition as a material discursive space. The curatorial process, when conceived as an evolving critical conversation between artists, curators and audiences, opens up new approaches to the mapping and analysis of the current relationship between women artists and motherhood in relation to conceptions of reproductive labour and curatorial care.

The reframing of organisational culture in terms of care is relevant here. As gallery director Jenny Richards (2016) recently commented, this pertains to caring for each other as workers, taking care of the organisation, the gallery program and of the public (124). In her article Support Acts: Curating, Caring and Social Reproduction, Helena Reckitt (2016) unpacks aspects of curatorial labour in relation to affective economies of care (7). Drawing on feminist social reproduction theory, Reckitt argues that a shift in focus is needed to redress political conditions under which institutions operate 'to look at how cultural projects deploy human, economic and material resources, and at what cost' (25). She argues that such an approach would 'develop different understandings of sustainability, value and social investment (...) nurturing the reproductive labour that sustains the living process of cultural production' (25-26).

Our feminist approaches and methods to exhibition making have emerged through an ongoing negotiation in curatorial art practice, and in the relational context of working with others in dialogic and collaborative ways. Framing this approach to exhibition making are our own experiences as artists - working with artists, curators, directors, media relations and public programs officers in a range of different institutional contexts from student exhibitions at university to large public art museums. This complex of relations highlights the embedded power hierarchies and the culture of administration that operates at all levels in the contemporary art industry. The question that arises is: as feminist curators, how can we reimagine institutional structures and ways of working within this relational field?

If we are to maintain feminist politics at the core of feminist curating it is necessary to consider the interrelational qualities of aesthetics and materialism in the museum. Angela Dimitrakaki and Lara Perry describe this as 'museum materialism' (2013: 1). Elke Krasny (2016) suggests a curatorial materialism is a:

critical investigation into the conditions and means of curatorial production, along with access to infrastructures and institutions, the relations between curators, artists, technicians, builders, educators, (...) sponsors, donors, and supporters and the engagement with the public (97). 
In this way, the curatorial process is reframed (not as choosing) but as socially engaged practice, always already existing in a field of relations. As Richter (2016) reminds us, 'thinking of curating as a form of producing knowledge (...) means consciously taking up a position in an ideologically contested space' (16). In presenting feminist exhibitions in contemporary art spaces, it is important to acknowledge the economic conditions and labour that support these structures. What is also highlighted is the importance of reproductive labour and care for art organisations. The task of the feminist curator is to place value on this labour; and to make visible contributions of women in these spaces of production - to emphasise feminist ways of working: including working against power hierarchies, exclusions and silencing; and working towards an ethics of care.

\section{CONCLUSION: STAYING AT HOME WITH THE POLITICS}

During the preliminary research and developmental planning for the feminist curatorial project Creative Dystocia, it has become clear to us that the false dichotomy of art-making and mothering has been carefully maintained over time, even throughout and after the explicitly feminist art movements of the second wave. While an emphasis on the structural sexism that underpins artist-mothers' disadvantage and an explicit connection between creativity and community wellbeing is a focus of some strategic projects around the globe, in Australia the emphasis is still very much on the acknowledgement and reiteration of an artist-mother identity and representations of motherhood. In all cases however, there is still a keen sense among artists that motherhood is constructed as an impediment to a successful art career, but does not need to be an impediment to a creatively successful art practice. By using feminist curatorial approaches, we are finding the gaps in current discussions and recognising that 'mothering' or as Ukeles called it, 'maintenance' labour (Ukeles, 1969), is actually the lifeblood of our remarkably precarious sector. By calling in the voices and creative expression of women artists across the mothering spectrum, as well as the carers of the art world, we are starting to map how individual artists and artworkers find themselves enmeshed in a complex structural matrix. This system appears to delight in sending highly contradictory signals regarding any shape women artist's careers may take. These circumstances have been integral to the development of Creative Dystocia, an artist-driven curatorial project yet to be born. Culminating in an exhibition and collaborative publication in 2020, this project is embracing these multiple perspectives and allowing contradictions to co-exist in both the content and form. In the local context, what is needed is a deeper engagement with the politics of care and art practice.

\section{REFERENCES}

Aamalia, J. (2008). Mad, Bad Mothers and the Deviant Event: Catherine Bell and the Maternal Instinct. N.Paradoxa, $22,69-75$.

Alexander, E. (2014). Tracey Emin: 'There are good artists that have children. They are called men'. The Independent. 3 October. Available at: https://www.independent.co.uk/news/people/tracey-emin-there-are-good-artiststhat-have-children-they-are-called-men-9771053.html (Accessed 11 October 2017).

Art/Mums. (2018). Residency: Art/Mums Collective. Available at https://doingfeminism-sharingtheworld.tumblr. com/post/170467272999/residency-artmums-collective (Accessed 20 February 2017).

Artsnight. (2015). The Pram in the Hall. Ep. 2/30. BBC TWO. Available at https:/ /www.bbc.co.uk/mediacentre/proginfo/2015/26/artsnight (Accessed 6 March 2019).

Baert, R. (2000). Historiography/Feminisms/Strategies. n.paradoxa: international feminist art journal, March 2000(12), 6-9.

Balla, P. (2018). Walking in deadly blak women's footprints. Artink, 38(2), 22-29.

Bell, C. (2011). Cooking up Crimes and Maternal Misdemeanours: From Food Ritual to Transgressive Performances. Double Dialogues, 15. Available at: http:/ /www.doubledialogues.com/article/ cooking-up-crimesand-maternal-misdemeanours-from-food-ritual-to-transgressive-performances (Accessed 4 June 2018).

Brooks, G. S. and Daniluk, J. C. (1998). Creative labors: The lives and careers of women artists. The Career Development Quarterly; Alexandria, 46(3), 246-261. https://doi.org/10.1002/j.2161-0045.1998.tb00699.x

Buller, R. E. (2012). Reconciling art and mothering. Burlington, VT: Ashgate Publishing Company.

Castagna, F. (2015). Who Gives a Shit? On motherhood and the arts. Southerly Journal. Available at: http://southerlyjournal.com.au/2015/11/25/who-gives-a-shit-on-motherhood-and-the-arts (Accessed 2 March 2018).

Chernick, M. and Klein, J. (Eds.). (2011). The M Word: Real Mothers in Contemporary Art. Toronto: Demeter Press.

Ciciola-Izzo, R. (2014). Mothering/Art: A Journey into Selfhood, Motherhood and Art Education through Personal Works (Master's Thesis), Concordia University. 
Clayton, L. (n.d.) An Artist Residency in Motherhood. Available at: http:/ /www.artistresidencyinmotherhood.com (Accessed 3 November 2018).

Crane, C. J. (2011). Portrait of the ARTIST as a MOTHER. Herizons, Winter, 20-23, 3.

Deepwell, K. (2006). Feminist Curatorial strategies and Practices since the 1970s. In New Museum Practice and Theory: An Introduction, edited by Janet Marstine, 64-80. Oxford: Blackwell Publishing. https://doi.org/10.1002/9780470776230.ch2

Dhillon, K. and Francke, A. (2016). The C-Word: Motherhood, Activism, Art, and Childcare. Studies in the Maternal, 8(2), 12. https://doi.org/10.16995/sim.226

Dimitrakaki, A. and Perry, L. (2013). Politics in a Glass Case: Feminism, Exbibition Cultures and Curatorial Transgressions. Liverpool: Liverpool University Press.

Dimitrakaki, A. and Perry, L. (2016). Constant Redistribution: A Roundtable on Feminism, Art and the Curatorial Field. Journal of Curatorial Studies, 2, no. 2 (2013), 226. https://doi.org/10.1386/jcs.2.2.218_1

Donner, C. (2016, July 18). Who Cares for Whom? Parenthood in the Creative Community. Available at: https://www.culturalreproducers.org/2016/07/who-cares-for-whom-parenthood-in.html

Foley, P. J. W. (1986). The Dual Role Experience of Artist Mothers (Ph.D.). Northwestern University, United States Illinois.

Gilligan, C. (1982). In a Different Voice: Psychological Theory and Women's Development. Cambridge, Mass.: Harvard University Press.

Gratton, E. C. (2017, April 5). Why artists don't have kids. Available at: https://www.artshub.com.au/newsarticle/opinions-and-analysis/trends-and-analysis/emma-clark-gratton/why-artists-dont-have-kids-253482 (Accessed 2 May 2017).

Heath, J. (2013). Negotiating the Maternal: Motherhood, Feminism, and Art. Art Journal, 72(4), 84-86. https://doi.org/10.1080/00043249.2013.10792867

Hedlin Hayden, M. and Sjoholm Skrubbe, J. (2010). Feminisms is Still Our Name: Seven Essays on Historiography and Curatorial Practices. Newcastle upon Tyne: Cambridge Scholars Publishing.

Hoffman, J. (2009). Editorial. The Exbibitionist Issue 1. Available at: http://theexhibitionist.com/archive/exhibitionist-1 (Accessed 9 March 2015).

Horne, V., K. Lloyd, J. Richards and C. Spencer. (2016). Taking Care Feminist Curatorial Pasts, Presents and Futures. On Curating: Curating in Feminist Thought, (29), 116-129.

Humphrys, E. (2019). How labour built neoliberalism: Australia's accord, the labour movement and the neoliberal project. Leiden: Brill. https://doi.org/10.1163/9789004383463

Jigarjian, M. and Mestrich, Q. (2015). How we do both: art and motherhood (2nd edition.). New York: Secretary Press.

Kirschenbaum, R. J. and Reis, S. M. (1997). Conflicts in Creativity: Talented Female Artists. Creativity Research Journal, 10(2-3), 251-263. https:// doi.org/10.1080/10400419.1997.9651224

Klenyánszki, C. (n.d.) Mothers in Arts / Statement. Available at: http://www.mothersinarts.com/statement

Kosmala, K. (2017). Becoming Imperceptible M/Other: Negotiating Porous Multiple Selves. N.Paradoxa, 39, 8695.

Krasny, E. (2016). Curatorial Materialism. A Feminist Perspective on Independent and Co-Dependent Curating. On Curating: Curating in Feminist Thought, (29), May, 96-106.

Kutis, B. (2013). Artist-parents Nature, nurture, and identity in contemporary art. Ph.D. thesis. University of Delaware, United States - Delaware.

Lake, M. (1999). Getting equal: the history of Australian feminism. St Leonards, N.S.W: Allen \& Unwin.

Larsen, D. P. (2006). Rethinking the Monumental: The Museum as Feminist Space in the Sexual Politics Exbibition, 1996 (Graduate Theses and Dissertations). Available at: http://scholarcommons.usf.edu/etd/3882

Letherby, G. (2018). To Be or Not To Be (a Mother): Telling academic and personal stories of mothers and others., in G. Rye, V. Browne, A. Giorgio, E. Jeremiah, and A. L. Six (Eds.), Motherhood in Literature and Culture: interdisciplinary perspectives from Europe, (pp. 241-255). Abingdon, Oxon; New York N.Y: Routledge.

Lindau, E. A. (2016). 'Mother Superior': Maternity and Creativity in the Work of Yoko Ono. Women and Music: $A$ Journal of Gender and Culture, 20, 57-76. https://doi.org/10.1353/wam.2016.0003

Liss, A. (2004). Maternal Rites: Feminist Strategies. N.Paradoxa, 14, 24-31.

Liss, A. (2009). Feminist Art and the Maternal (New edition). University of Minnesota Press.

McNamara, A. E. (2012). Six rules for practice-led research. Text: Journal of Writing and Writing Courses, 14, 1-15.

McQuire, A. (2015, March 5). All Feminists Are Created Equal, But Some Are More Equal Than Others. Available at https://newmatilda.com/2015/03/05/all-feminists-are-created-equal-some-are-more-equal-others (Accessed 9 March 2019).

Miller, D. L. (2016). Gender and the Artist Archetype: Understanding Gender Inequality in Artistic Careers. Sociology Compass, 10(2), 119-131. https://doi.org/10.1111/soc4.12350 
Moreton-Robinson, A. (2000). Talkin' up to the white woman: Aboriginal women and feminism. St Lucia, Qld: University of Queensland Press.

National Museum of Women in the Arts. (n.d.). Get the Facts. Available at https://nmwa.org/advocate/get-facts (Accessed 16 May 2019).

Needham, C. (2016). MUM. Stockroom Space, Kyneton, Victoria. Available at http://ninaross.com.au/wpcontent/uploads/2016/06/MUM-essay-2016.pdf (Accessed 4 March 2018).

Neuendorf, H. (2016). Marina Abramovic Says Kids Hold Back Female Artists. ArtNet News. July 25. Available at https:// news.artnet.com/art-world/marina-abramovic-says-children-hold-back-female-artists-575150 (Accessed 5 October 2017).

Palmer, D. S. (2016). Go Pro: The Hyper-Professionalization of the Emerging Artist. March 9. Available at http:/ / www.artnews.com/2016/03/09/go-pro-the-hyper-professionalization-of-the-emerging-artist (Accessed 13 October 2018).

Pedersen, C. and Haynes, R. (2015). Double Blind: Supervising Women as Creative Practice-Led Researchers. Educational Philosophy and Theory, 47(12), 1265-1276. https://doi.org/10.1080/00131857.2015.1035631

Perkovic, J. and Balla, P. (2018). Paola Balla: Blak Matriarchy. Available at: https:/ / assemblepapers.com.au/2018/04/26/paola-balla-blak-matriarchy (Accessed 6 March 2019).

Piirto, J. (1991). Why are there so few? (Creative women: Visual artists, mathematicians, musicians). Roeper Review, 13(3), 142. https:/ / doi.org/10.1080/02783199109553340

Power, R. (2008). The divided heart: art and motherhood. Fitzroy, Vic.: Red Dog.

Puglise, N. (2016). Marina Abramović says having children would have been 'a disaster for my work'. The Guardian. July 27. Available at https://www.theguardian.com/artanddesign/2016/jul/26/marina-abramovic-abortionschildren-disaster-work (Accessed 5 October 2017).

Reckitt, H. (2016). Support Acts: Curating, Caring and Social Reproduction. Journal of Curatorial Studies, 5(1), 6-30. https://doi.org/10.1386/jcs.5.1.6_1

Reilly, M. and Perry, L. (2016). Living the Revolution a Dialogue between Maura Reilly \& Lara Perry. On Curating: Curating in Feminist Thought, May 2016(29), 50-52.

Reis, S. M. (2002). Toward a Theory of Creativity in Diverse Creative Women. Creativity Research Journal, 14(3-4), 305-316. https://doi.org/10.1207/S15326934CRJ1434_2

Richter, D. (2016). Feminist Perspectives on Curating. On Curating: Curating in Feminist Thought, May 2016(29), 6475.

Robinson, H. (2013). Feminism Meets the Big Exhibition: Museum Survey Shows since 2005. Revista Anglo Saxonica, 3(6), 129 - 152.

Romensky, L. (2016). Art exhibition explores the beautiful and ugly side of motherhood [Text]. Available at: https://www.abc.net.au/news/2016-06-08/the-beautiful-and-ugly-side-of-motherhood-in-photos/7493572 (Accessed 5 March 2018).

SBS. (2018). SBS and Yumi Stynes tackle the question, 'Is Australia Sexist?’ Available at: https://www.sbs.com.au/ programs/is-australia-sexist/article/2018/11/01/sbs-and-yumi-stynes-tackle-question-australia-sexist (Accessed 1 November 2018).

Simic, L. (2008). Impossible Expectations and Everyday Interventions: A Document of Maternity Leave. N.Paradoxa, 22, 79-83.

Smith, H., and Dean, R. (2009). Practice-led research, research-led practice in the creative arts. Edinburgh: Edinburgh University Press.

Sorkin, J. (2007). The Feminist Nomad: The All-Women Group Show. In WACK! Art and the Feminist Revolution, edited by Cornelia Butler and Lisa Gabrielle Mark, 458-471. Los Angeles, CA: The Museum of Contemporary Art and MIT Press.

Spivak, G. C. (1987). In Other Worlds: Essays in Cultural Politics. London \& New York: Routledge.

Stohs, J. H. (1992). Career Patterns and Family Status of Women and Men Artists. The Career Development Quarterly 40, 223-233. https://doi.org/10.1002/j.2161-0045.1992.tb00328.x

Stuart, J. (2011). Procreation, Creative Work, and Motherhood. Psychoanalytic Inquiry, 31(4), 417-429.

Stuart, J. (2011). Procreation, Creative Work, and Motherhood. Psychoanalytic Inquiry, 31(4), 41-429. https://doi.org/10.1080/07351690.2010.516234

Summers, F. and Clarke, A. 2015. In-betweenness: being mother, academic and artist. Journal of Family Studies, 21(3), 235-247. https://doi.org/10.1080/13229400.2015.1058846

Sutherland Harris, A. and Nochlin, L. 1976. Women Artists 1550 - 1950. Los Angeles and New York: Los Angeles County Museum of Art and Alfred A Knopf.

The CoUNTess Report. (2016) Available at: http://thecountessreport.com.au (Accessed 20 May 2017).

Throsby, D. and Petetskaya, K. (2017). Making Art Work: an economic study of professional artists in Australia. Sydney: Australia Council for the Arts. 
Townsend, R. B. (2017, October 5). Taking Note: How About Those Undergraduate Arts Majors? Available at: https://www.arts.gov/art-works/2017/taking-note-how-about-those-undergraduate-arts-majors (Accessed 16 May 2018)

Ukeles, M. L. (1969) MIERLE LADERMAN UKELES. New York: Feldman Gallery.

Unrau, M. D. (2012). Play, Battling: Representing Resistant Mothers with 'Mothers Who Refuse to Choose'. Journal of the Motherbood Initiative for Research and Community Involvement, 3(2), 17-32.

Williams, A. (2016). Must motherhood kill your creative career? Available at: http:/ /www.dailylife.com.au/life-and -love/real-life/must-motherhood-kill-your-creative-career-20160217-gmwqiq.html (Accessed 5 October 2017).

World Economic Forum. (2017). Global Gender Gap Report 2017 (Global Gender Gap Report). Geneva, Switzerland: World Economic Forum. Available at: http://wef.ch/2fhXRju (Accessed 15 October 2018).

Zwirn, S. G. (2006). Artist or Art Teacher: The Role of Gender in Identity Formation and Career Choice. Teaching Artist Journal, 4(3), 167-75. https://doi.org/10.1207/s1541180xtaj0403_4

Citation: Pedersen, C. and Haynes, R. (2019). Curating 'Creative Dystocia': Exhibiting the Relationship between Artists, Identity and Motherhood in Twenty-first Century Australian Art. Feminist Encounters: A Journal of Critical Studies in Culture and Politics, 3(1-2), 05. https:// doi.org/10.20897/femenc/5911

Copyright (C) 2019 by Author/s and Licensed by Lectito BV, Netherlands. This is an open access article distributed under the Creative Commons Attribution License which permits unrestricted use, distribution, and reproduction in any medium, provided the original work is properly cited. 